\title{
The effect of group training implemented on hemodialysis patients for their stress management, psychosocial adjustment and self-care strength
}

\author{
Hülya Fırat Kılıç ${ }^{1}$ \\ Şule Ecevit Alpar ${ }^{2}$
}

\begin{abstract}
Purpose: The current study was made with the objective of determining the effect of group training implemented on hemodialysis patients for their stress management, psychosocial adjustment and self-care strength.

Method and Material: The single group pre-experiment model with pre-test - post-test was used. The participants were selected from a group of 100 patients who were undergoing treatment in 2011, at the Hemodialysis Units of two state hospitals in North Cyprus. The sampling composed of 90 patients who met the screening criteria and fully consented to take part in the study conducted between January 2011 and June 2011. The researcher collected data before training and 3 months after training by using the Patient Sociodemographic Characteristics Form, Psychosocial Adjustment to Illness Scale-Self-Report, Self-care Strength Evaluation Scale and the Hemodialysis Stressor Scale.
\end{abstract}

Results: It was observed that as the stressors increased in hemodialysis patients, the self-care strength and adjustment to illness decreased. Additionally, it was also found that as the self-care strength increased the adjustments to illness also increased. Furthermore, it was determined that the stressors of female patients were higher compared to male patients. The adjustment of patients working and those receiving treatment at Institution 2 were found to be lower.

Conclusions: It was concluded that there was a decrease in the stressors perceived by hemodialysis patients who had undergone the training program. Moreover, these patients also evidenced an increase in the adjustment to illness and in self-care strength after the training program had been implemented.

Keywords: Dialysis; nursing; self-care; psychosocial adjustment; stress.

\footnotetext{
1 Assist. Prof. Dr., Eastern Mediterranean University, Faculty of Health Sciences, Department of Nursing, Famagusta, North Cyprus, via Mersin 10 Turkey; hulyafirat81@gmail.com

2 Prof. Dr., Marmara University, Faculty of Health Sciences, Department of Nursing, Istanbul, Turkey; salpar7@gmail.com
} 
Fırat Kılıç, H., Alpar Ş. E. (2016). The effect of group training implemented on hemodialysis patients for their stress management, psychosocial adjustment and self-care strength. International Journal of Human Sciences, 13(1), NNN-NNN. doi:10.14687/ijhs.v13i1.3422

\section{Introduction}

Hemodialysis (HD) is a long-term form of therapy, which is the Renal Replacement Therapy (RRT) method that is preferred the most in the Turkish Republic of Northern Cyprus (TRNC). It is evidenced that this therapy is applied in approximately $80 \%$ of the Chronic Renal Insufficiency (CRI) patients (Özçürümez et al., 2003). End Stage Renal Disease (ESRD) patients are subjected to a complex therapy regime and changes in lifestyle, which include dialysis and a large number of dietary restrictions (Tsay \& Healstead, 2001). Research has shown that HD has various affects on patients lives including physiological needs, self-esteem, mental status, social relations and roles of individuals (Vicdan \& Karabacak, 2014).

Besides dialysis therapy being very time-consuming, it comprises a significant place in the daily lives of patients. According to studies in the literature, the proportion of dialysis patients participating in sports, social activities and working in a paid job is lower compared to healthy individuals. Consequently, receiving dialysis therapy has a negative influence for participating in many different areas of life and quality of life (Jansen et al., 2010; Ören \& Enç, 2013).

Adjustment is defined as the patients' acceptance and implementation of the proposals and treatments given by the health professionals (Kara, 2007). The failure of adjustment to a therapy regime given to patients is among the most important problems confronted by health care in the present day. The maladjustments of patients in the course of their therapy increase morbidity, mortality and economic problems. According to studies in the literature, it was observed that $20 \%$ to $80 \%$ of the dialysis patients failed to adjust to the therapy regime, to a diet and to the other lifestyle changes (Christensen et al., 2002).

Stress is defined as a "particular relationship between the person and the environment that is appraised by the person as taxing or exceeding his or her resources and endangering his or her well-being" (Ahmad \& Al Nazly, 2014). It has been proposed that chronic diseases are a primary or secondary stressor for the individual and their family (Vicdan \& Karabacak, 2014). There is evidence to suggest that the fear of death felt in CRI, the loss of physical strength and endurance, experiencing economic difficulties, restrictions of diet and liquid intake, and dependence on medical therapy in patients can also be the cause of perceiving this illness as an excessive stressor (Özçürümez et al., 2003).

According to Orem, self-care is keeping one's end up for preserving the life, health and wellbeing of the individual. It is said that this skill can develop in time through communication, culture, education and interaction (Bağ \& Mollaoğlu, 2010). The self-care levels of HD patients are important from the aspect of their skills at managing the symptoms of their diseases. Patients who have high self-care strength can meet their self-care needs, can assume responsibilities for their own health and can meet their daily life activities in an independent manner (Denyes et al., 2001). Research in this filed has shown that there is a relationship between self-care strength and adjustment to therapy; health development behaviors and physical and psychological symptoms (Bane et al., 1993; Mollaoğlu, 2005; Yurtsever \& Kuyurtar, 2005).

Nurses, as important members of the health team, have great responsibilities for patients coping effectively with stress, for providing adjustment to therapy and for communicating at every stage of the illness with patients. As part of their responsibilities, it is necessary for nurses to provide health training to patients for adjustment to therapy.

The success in HD therapy method, to a great extent, is connected to the patients' adjustment to therapy (Kutnet et al., 2002). Nevertheless, behaviors of the individual in adjustment to therapy are determined with the level of being suitable for the suggestions made by health care professionals (Takaki et al., 2002). Despite the importance of adjustment to therapy, it is generally known that maladjustment to therapy is widespread among HD patients (Christensen, 2000; Cvengros, 2004; Rosner, 2006).

Therapy implemented by health professionals for chronic diseases and the objectives of nursing care are not only to extend the lifespan of patients, but at the same time, they are to plan 
Fırat Kılıç, H., Alpar Ş. E. (2016). The effect of group training implemented on hemodialysis patients for their stress management, psychosocial adjustment and self-care strength . International Journal of Human Sciences, 13(1), NNN-NNN. doi:10.14687/ijhs.v13i1.3422

and implement what is needed for a high quality lifespan (Suet-Ching, 2001; Akyol \& Karadakovan, 2002).

Dialysis patients need to deal and cope with various aspects of their disease. (Parvan et al., 2015). Knowing the sources that constitute stress and developing effective coping strategies are important on behalf of developing adjustment to the treatment by HD patients. Providing adjustment to treatment in the HD patients is important on behalf of their health status, wellbeing and developing their quality of life (Akin et al., 2010).

Stress, self-care and adjustment have become important concepts in the care of HD patients. Developing methods of coping with stress and psychosocial adjustment to illness can positively affect the self-care behaviors of the individual. Consequently, training programs implemented for increasing the adjustment and self-care strength of patients and for their coping with stress acquire importance for increasing their self-care strength by increasing the adjustment of patients to illness.

Although there are studies in the literature aimed at the problems of dialysis patients, the studies related to psychosocial adjustment, stress management and self-care are limited and inadequate (Ahmad \& Al Nazly, 2004; Parvan et al., 2015; Mollaoğlu, 2011). Furthermore, no study was encountered that examined in detail the relationship among the psychosocial adjustment, stress management and self-care levels of dialysis patients.

\section{Purpose}

The current study was planned with the aim of determining the effect of group training implemented on HD patients for their stress management, psychosocial adjustment and self-care strength, by taking into account the contributions of nurses for preserving and raising the health of individuals. Additionally, It was anticipated that the result from the current study provided contributions to nursing interventions

\section{Hypotheses of the study}

$\mathbf{H}_{1}$ : It was expected that after the training program implemented on HD patients that the point averages on the Hemodialysis Stressor Scale (HSS) would be different at a significant level compared to before the program.

$\mathbf{H}_{2}$ : It was expected that after the training program implemented on HD patients that the point averages on the Psychosocial Adjustment to Illness Scale--Self Report (PAIS-SR) scale would be different at a significant level compared to before the program.

$\mathbf{H}_{3}$ :It was expected that after the training program implemented on HD patients that the point averages on the Self-care Strength Evaluation Scale for chronic dialysis patients would be different at a significant level compared to before the program.

\section{Method and Material}

\section{The place and time of the study}

The study was conducted on patients who were receiving therapy in the hemodialysis units at two state hospitals (Table 1) in Turkish Republic of Northern Cyprus (TRNC) between January 2011 and June 2011.

\section{Population and sample selection}

The participants were selected from a group of 100 registered patients in 2011 at the Hemodialysis Units of two state hospitals. From those 100 patients, 90 individuals met the sampling criteria that accepted to participate in the study carried out between January 2011 and June 2011. Since the setting constituted the sampling, the sampling selection method was not applied. 
Firat Kılıç, H., Alpar Ş. E. (2016). The effect of group training implemented on hemodialysis patients for their stress management, psychosocial adjustment and self-care strength. International Journal of Human Sciences, 13(1), NNN-NNN. doi:10.14687/ijhs.v13i1.3422

Inclusion criteria for this study comprised of being literate, being 18 years of age or older, volunteering to participate in the study, being on the same treatment modality for at least 6 months, having ability to establish communications with ease and not having psychiatric complaints.

Table 1 Characteristics of the institutions

\begin{tabular}{|l|l|l|l|l|}
\hline & $\begin{array}{l}\text { Total number } \\
\text { of beds }\end{array}$ & $\begin{array}{l}\text { Total number } \\
\text { of nurses }\end{array}$ & $\begin{array}{l}\text { Number of } \\
\text { machines in the } \\
\text { HD unit }\end{array}$ & $\begin{array}{l}\text { Number of } \\
\text { nurses in the HD } \\
\text { unit }\end{array}$ \\
\hline Institution 1 & 495 & 380 & 20 & 13 \\
\hline Institution 2 & 156 & 130 & 5 & 4 \\
\hline
\end{tabular}

\section{Type of study}

The design of the study was a single group pre-experimental model with pre-test and post-test, with the aim of determining the effect of group training on stress management, psychosocial adjustment and self-care strength, for HD patients.

\section{The variables}

Dependent variables: They are composed of the Psychosocial Adjustment to Illness Scale-Self Report Points, Self-care Strength Evaluation Scale Points for Chronic Dialysis Patients and Hemodialysis Stressor Scale Points.

Independent variables: They are composed of sociodemographic characteristics, such as institution, gender, age, marital status, work status and educational status.

\section{Data Collection}

\section{Data collection method}

Group training was given to patients participating in the study according to the training guide prepared by the researcher. The data were collected with the two-stage pre-test - post-test method before training and three months after training. The scales were re-applied on the patients 3 months after training in order to evaluate the effectiveness of the training implemented.

Pre-interviews were held with the patients and a suitable time for group training was determined. Training was delivered to patients in a suitable, quiet, light and airy room at the HD unit. The training book was prepared by the researcher (Firat, 2010). The training program implemented on each group was composed of 4 sessions and each group training lasted for an average of one hour. In the first session, the scales used in the study were implemented. In the second session, information was given related to the etiology of the diseases and the self-care implementations. In the third session, training was given on the subjects of interpersonal relations, stress management and social support factors. Lastly, the fourth session was given 3 months later and the scales implemented in the study were repeated.

\section{Data collection tools}

The Patient Sociodemographic Characteristics Form, Psychosocial Adjustment to Illness Scale - Self-Report (PAIS-SR), Hemodialysis Stressor Scale (HSS) and Self-care Strength Evaluation Scale were used to collect data. The Patient Sociodemographic Characteristics Form was composed of 19 questions, which included the sociodemographic characteristics of the patients and information related to their illness.

Psychosocial Adjustment to Illness Scale - Self-Report (PAIS-SR): The PAIS-SR is a scale developed by Derogatis and Lopez in 1983 and it measures the psychosocial adjustment to 
Firat Kilıç, H., Alpar Ş. E. (2016). The effect of group training implemented on hemodialysis patients for their stress management, psychosocial adjustment and self-care strength. International Journal of Human Sciences, 13(1), NNN-NNN. doi:10.14687/ijhs.v13i1.3422

illness (Derogatis, 1986). This scale measures individuals with other individuals and the reciprocal interaction with institutions, which constitute the sociocultural environment. The PAIS-SR is composed of 46 items and 7 sub-groups. These sub-groups are as follows: Orientation to Health Care (P1), Professional/Work Environment (P2), Family Environment (P3), Sexual Relations (P4), Extended Family Relations (P5), Social Environment (P6) and Psychological Area (P7). The minimum and maximum points obtained from the scale are between $0-138$, and the intervals between the sub-group points varied between P1: 0-24, P2: 0-18, P3: 0-24, P4: 0-18, P5: 0-15, P6: 0-18 and P7: 0-21. In this scale, low points show "good psychosocial adjustment" to illness and high points show "poor psychosocial adjustment" to illness. The domain intercorrelation average has been found to be .28 , and reliability coefficient alpha for patients range from .63 to .87 (Derogatis, 1986). The validity and reliability study of the scale for Turkey was made by M Aygün Adaylar and it was determined that the reliability coefficient of the scale for all scales was 0.94 (Adaylar, 1995). In the present study, the Cronbach's alpha coefficient for the total PAISSR scale was .94, and subscale reliabilities ranged from .73 to .92.

The Self-care Strength Evaluation Scale for Chronic Dialysis Patients: It is a scale developed in 2010 by Besey Ören for hemodialysis and peritoneal dialysis patients (Ören, 2010). The scale was used with the objective of evaluating the self-care strength of the patients. In this study, the Cronbach's alpha value was .75 for all scales. The Self-care Strength Scale (SSS) is composed of 25 items and is a triple Likert-type scale scored between 0-2. The points obtained from the scale are between $0-44$. In the evaluation, low points were evaluated as being not good, whereas, high points were evaluated as being good for self-care strength. The Cronbach's alpha value was .88 in our study.

Hemodialysis Stressor Scale (HSS): The scale that was developed by Baldree et al in 1982 with the original name of the Hemodialysis Stressor Scale, was adapted to the Turkish society by Bergüzar Kara (Kara, 2006). The scale was used with the objective of assessing the stressors related to the treatment of chronic HD patients. The physiological (6 items) and psychosocial stressors (23 items) are listed in the HSS and are perceived to be related to the therapy of HD patients. The Physiological Hemodialysis Stressor (H1) sub-dimension points vary between 6-30 points and the Psychosocial Hemodialysis Stressor (H2) sub-dimension points vary between 23-115 points. _The total HSS points are between 29 and 145. A rise in the points obtained from the scale indicates a rise in the level of stress perceived (Kara, 2006). The Cronbach's alpha value was stated to be 0.77 in the validity and reliability study of the scale that was adapted to Turkish (Kara \& İscan, 2006). The Cronbach's alpha for the total scale in this study was 0.91 .

\section{Research ethics}

All participants were informed the aim of the study as well as the implementations that would be made. They were also made aware that information would remain confidential. The patients who accepted to participate in the study filled and signed an informed consent form. Furthermore, the research commenced after receiving the written permissions from the related institutions and after receiving the approval of the Clinical Research Pre-evaluation Committee of the University, Institute of Health Sciences.

\section{Evaluation of data}

The entering and evaluating of data was made with the SPSS version 13.0 program under the consultancy of a statistical expert. The single sampling Kolmogorov-Smirnov test was implemented with the objective of determining whether or not the points obtained from the scales used in the study showed a normal distribution. Percentages were used in the distribution of the sociodemographic characteristics and attributes related to illness. The Wilcoxon SignedRank test was used in the comparison of the values of the scales before and after implementation. 
Firat Kilıç, H., Alpar Ş. E. (2016). The effect of group training implemented on hemodialysis patients for their stress management, psychosocial adjustment and self-care strength. International Journal of Human Sciences, 13(1), NNN-NNN. doi:10.14687/ijhs.v13i1.3422

The Spearman's Rank Correlation Coefficient was used in the comparison of the scale points with each other. The "Mann-Whitney U-test" and Kruskal Wallis H-Testi technique was implemented in the comparison of some variables and the difference points for the pre-test post-test of the scales.

\section{Results}

A great majority $(83.3 \%)$ of the patients composing the sampling group were treated at Institution 2. Of the patients, $51.1 \%$ were males, $40 \%$ were between $45-64$ years of age, $85.6 \%$ were married and $82.2 \%$ had never worked. Of the HD patients who participated in the study, $46.7 \%$ expressed that they had been having hemodialysis for between 1 and 4 years and $84.4 \%$ were having dialysis 3 times/week (Table 2).

A significant difference was found between the psychosocial and physiological subscale points for the HSS of the patients before and after training $(Z=-8.236, p<.001)$. It was determined that there was a decrease in the stressors perceived by the patients after training (Table 3).

As it can be observed in Table 3, a significant difference was found between the PAIS-SR scale and all subscale points of the patients before and after training $(\mathrm{Z}=-8,240, \mathrm{p}<.05)$. It was determined that there was an increase in adjustment to illness of the HD patients after training.

It was observed that there was a significant difference between the SSS points of the patients who participated in the study before and after training $(\mathrm{Z}=-8,197, \mathrm{p}<.05)$. It was determined that there was an increase in the self-care strength of patients after training (Table 3 ).

A significant relationship was found at a medium level in a significantly negative direction between the total points on the SSS and the HSS total and subscale points after training $(r=-.44$, $p=.001)$. Accordingly, as the general and subscale points on the HSS increased, the SSS points decreased (Table 4).

A relationship was found at a medium level in a significantly positive direction between the total HSS points and the total and subscale points on the PAIS-SR after training $(\mathrm{r}=.58$, $p=.01)$. Accordingly, as the HSS points increased, the PAIS-SR general and subscale points also increased (Table 4).

As it can be observed from Table 4, there was a significant negative relationship at a medium level between the SSS general points and the PAIS-SR general, health care orientation, vocational environment, family environment, social environment, extended family relationships and the psychological distress subscale points after training ( $\mathrm{r}=-.39, p=.01)$. Accordingly, as the general points on the Self-care Strength Scale increased, the general, health care orientation, vocational environment, family environment, social environment, extended family relationships and psychological distress subscale points decreased on the PAIS-SR.

As it can be observed from Table 5, a statistically significant difference was not observed for the HSS of the dialysis patients participating in the study and the subscale points with institution, age $(\mathrm{P}=.599)$, marital status $(\mathrm{P}=.717)$ and work status $(\mathrm{P}=.132)(\mathrm{p}>.05)$. A significant difference was observed on the HSS of the patients according to gender for the point differences on the psychosocial subscale $(\mathrm{P}=.032)$. According to this result, the HSS first subscale point difference of female dialysis patients was higher than the HSS first subscale point difference of male dialysis patients $(\mathrm{p}<.05)$.

The PAIS-SR of the dialysis patients participating in the study showed a significant difference for professional environment $(\mathrm{P}=.007)$, family environment $(\mathrm{P}=.042)$ and psychological area $(\mathrm{P}=.001)$ subscale point differences according to the institution variable of the patients. According to this result, the professional environment, family environment and psychological area subscale point differences on the PAIS-SR for dialysis patients receiving treatment at Institution 2 were higher than the professional environment, family environment 
Fırat Kılıç, H., Alpar Ş. E. (2016). The effect of group training implemented on hemodialysis patients for their stress management, psychosocial adjustment and self-care strength. International Journal of Human Sciences, 13(1), NNN-NNN. doi:10.14687/ijhs.v13i1.3422

and psychological area subscale point differences on the PAIS-SR for dialysis patients receiving treatment at Institution $1 \quad(\mathrm{p}<.05)$. (Table 6).

When it was examined according to work status of the dialysis patients, the health care orientation subscale points $(\mathrm{P}=.001)$ on the PAIS-SR of the dialysis patients who work in any job was higher $(\mathrm{p}<.05)($ Table 6$)$.

Also, as can be observed on Table 6, it was shown that there was not a statistically significant difference between the general and subscale point differences on the PAIS-SR with the variables of age $(\mathrm{P}=.454)$, gender $(\mathrm{P}=.140)$ and marital status $(\mathrm{P}=.223),(\mathrm{p}>.05)$.

\section{Discussion}

In the study made, it was determined that there was a decrease in the stressors perceived by HD patients after training $(p<.001)$. According to these results, it can be stated that the training program organized made a significant contribution to a decrease in the stress of HD patients. This study has found similar results with other studies, supporting the effectiveness of the training program in decreasing levels of stress. (Klang et al., 1998; Tsay \&lee, 2005). However, in the study by Hiçdurmaz and $\mathrm{O} z$ a statistically significant relationship was not encountered between the methods of coping with stress and the status of receiving training for hemodialysis in the hemodialysis patients (Hiçdurmaz \& Öz, 2009). Consequently, it can be thought that individuals, who do not receive sufficient training by not feeling this strength, will not be able to provide adjustment to their therapies, will become more dependent and will not be able to cope effectively with stressors.

The findings of this study show that there was an increase in adjustment to illness of the HD patients after training $(\mathrm{p}<.05)$ Similarly, Molaison and Yadrick conducted a 12 -week educational intervention for fluid control in a haemodialysis units, and they observed that improved knowledge helped patients adhere to the recommended weight gain restrictions ${ }^{34}$. Durna et al. found that patients who expressed that they had insufficient information were constrained in adjusting to therapy (Molaison \& Yadrick, 2003). In the study made by Türkmen and Çam with patients undergoing myocardial infarction, it was observed that the training implemented was effective in increasing the adjustments of patients (Türkmen \& Çam, 2012)

In the present study, it was observed that there was an increase in the SSS of HD patients after training $(\mathrm{p}<.05)$. Similarly, Bakoğlu et al. reported that the self-care strength of patients who complied with training given in the hospital was higher (Bakoğlu et al., 2009). In many studies carried out with patients having a chronic disease, it was determined that the training given to patients displayed a positive effect on the self-care activities of patients and their knowledge about their diseases (Jaarsma et al., 2000; Manns et al., 2005; Huang et al., 2005; Gallegos et al., 2006).

In the study made, as the HSS points increased, the PAIS-SR general and subscale points also increased $(\boldsymbol{p}=.01)$. According to these results, it can be stated that as the stressors increased in HD patients, the adjustment to illness decreased. Similarly, Courts reported that as the stressors of the patients increased, their adjustments to illness were affected negatively and as the HSS points increased, the PAIS-SR points also increased (Courts Fleming, 2000). Moreover, in this study, it was found that as the self-care strength of the patients rose, their adjustments to the illness also increased. Similarly, Lev and Owen found that patients who had high self-care strength could manage their illnesses better (Lev\& Owen, 1998).

HD patients are subjected to physiological and psychosocial stressors connected to lifestyle changes and potential losses.( C.inar et al., 2009). The findings of this study show that that there was not a statistically significant difference in the HSS and subscale points of the HD patients for institution, age, marital status, educational status and work status ( $\mathrm{p}>.05$ ). Also, similar to our study, in the study made by Ahmad and Nazly, a significant relationship was not found between stress and age (Ahmad \& Nazly, 2014). The study made on HD patients by 
Fırat Kılıç, H., Alpar Ş. E. (2016). The effect of group training implemented on hemodialysis patients for their stress management, psychosocial adjustment and self-care strength. International Journal of Human Sciences, 13(1), NNN-NNN. doi:10.14687/ijhs.v13i1.3422

Mok, while there was not a difference between the stress levels and the marital status and educational status, it was found that the physiological stressors subscale points of those 55 years of age and older were found to be higher compared to those 55 years of age and younger (Mok E $\&$ Tam, 2001). The findings of our study show that the stressors of female patients are greater $(\mathrm{p}<.05)$. This study showed similarities with other studies (Ahmad \& Nazly, 2014; Suet-Ching, 2001; Molaison \& Yadrick, 2003). When the findings in the literature were evaluated in relation to the regulator, producer and reconciliatory roles of women within the family, along with considering the burdens and responsibilities brought by the disease in HD and its treatment, it could be understood that a large proportion of patients' time is consumed with the illness, thus disturbing and changing role performance and family processes. These adverse affects could be encountered as great stressors and are inevitably more likely to affect women compared to men.

In the current study it was found that the PAIS-SR at professional environment, family environment and psychological area subscale of the patients receiving treatment at Institution 2 was lower for the PAIS-SR $(\mathrm{p}<.05)$. It can be stated that it stemmed from factors, such as the fact that Institution 2 was a peripheral hospital, that there were no trained dialysis nurses providing health care and that there were insufficient dieticians and psychological support. When the PAIS-SR points were examined according to work status, it was found that the adjustment in working HD patients was low $(\mathrm{p}<.05)$. In contrast to our study, in the study made by Akça and Çınar on diabetic patients, it was found that the adjustments of retired persons was worse (Akça \& Çinar, 2008). The fact that the psychosocial adjustments of those working was worse can be explained by the reflection to work life of the physical and psychological problems experienced by patients who are dependent on dialysis and the threat of losing their work.

\section{Conclusion and recommendations}

In conclusion, it was found that there was a decrease in the stressors perceived by the patients and an increase in adjustment to illness and in self-care strength of HD patients after the training program had been implemented and it was observed that the hypotheses determined were accepted. According to this result, it is proposed that the psychosocial adjustment levels of patients should be evaluated. In particular, those patients whose level of adjustment is poor should be given the opportunity to express themselves through interventions such as consultancy and training. Additionally, it could be seen beneficial to organize psycho-educational programs for the HD patients for increasing their self-care strengths and for developing methods of coping with stress.

\section{Ackknowledgements}

We are grateful to Ellen Yazar and Yeşim Firat for their English language advice. We also thank Murat Çakar for his statistical evaluations.

\section{References}

1. Adaylar, M. (1995). The Attitudes, Adaptation, Perception and Self-care Orientations to Illnesses of Individuals Who Have a Chronic Disease. PhD diss., Istanbul University, Institute of Health Sciences, İstanbul.

2. Ahmad, MM., \& Al Nazly, EK. (2014). Hemodialysis: Stressors and Coping Strategies. Psychol Health Med, DOI: 10.1080/13548506.2014.952239.

3. Akça, AT., \& Çınar, S.(2008). Comparison of Psychosocial Adjustment in People with Diabetes with and without Diabetic Foot Ulceration. Australian Journal of Advanced Nursing, 24(4): 87-96. 
Firat Kilıç, H., Alpar Ş. E. (2016). The effect of group training implemented on hemodialysis patients for their stress management, psychosocial adjustment and self-care strength. International Journal of Human Sciences, 13(1), NNN-NNN. doi:10.14687/ijhs.v13i1.3422

4. $\quad$ Akıı., S., Taşköprü İ., Özdilli K., Yeşiltepe G., Öztürk B., \& Durna Z.(2010). The Functional Performance Status, Quality of Life and Hemodialysis Stressors of Haemodialysis Patients. Hemsirelikete Ë̆itim ve Arasstrma D. 7(3):16-25.

5. Akyol., AD., \& Karadakovan., A. (2002). The Investigation of Influence Factors on Selfcare Agency and Quality of Life on Hemodialysis Patients. Ege Tip D. 41(2):97-102.

6. Bağ, E., \& Mollaoğlu., M. (2010). The Evaluation of Self-care and Self-efficacy in Patients Undergoing Hemodialysis. J Eval Clin Prac . 16(3):605-10.

7. Bakoğlu., E., Şekerci K., Yaman., S \& Çevik M. (2009). Self-care Strength in Peritoneal Dialysis Patients. Frrat Sağllk Hiz. D. 4(11):65-78.

8. Baldree KS., Murphy S., \& Powers., MJ. (1982). Stress Identification and Coping Patterns on Hemodialysis. Nurs Res. 31(2):107-12.

9. Bame SI., Peterson N., \& Wray NP.(1993). Variation in Hemodialysis Patient Compliance According to Demographic Characteristics. Soc Sci Med. 37(8):1035-43.

10. Christensen AJ. (2000). Patient-by-treatment Context Interaction in Chronic Disease: A Conceptual Framework for the Study of Patient Adherence. Psychosom Med. 62:435-43.

11. Christensen, AJ., Moran PJ., Wiebe JS., Ehlers SL., \& Lawton WJ. (2002). Effect of Behavioral Self-Regulation Intervention on Patient Adherence in Hemodialysis. Health Psychol . 21(4):393-7.

12. Courts Flemin, N. (2000). Psychosocial Adjustment of Patients on Home Hemodialysis and Their Dialysis Partners. Clin Nurs Res. 9(2):177-90.

13. Cvengros, JA., Christensen, AJ., \& Lawton WJ. (2004). The Role of Perceived Control and Preference for Control in Adherence to a Chronic Medical Regimen. Ann Behav Med 27:155-61

14. Çınar, S., Barlas, GU., \& Alpar, SE. (2009). Stressors and Coping Strategies in Hemodialysis Patients. Pak J Med Sci. 25(3):447-52.

15. Denyes, MJ., Orem, DE., \& SozWiss, GB., (2001). Self-care: A Foundational Science. Nurs Sci Q. 14(1):48-54.

16. Derogatis, LR. (1986). The Psychosocial Adjustment to Illness Scale (PAIS). J Psychosom Res. 30(1):77-91.

17. Durna, Z., Özcan Ş., Erdoğan., N. \& Yeşiltepe, G.(2000). Quality of Life and Levels of Social Support of Patients Receiving Regular Hemodialysis Therapy. Hemsirelik Forumu. $3(2): 6-14$.

18. Firat H., (2010). Training Guide for Hemodialysis Patients. Turkish Republic of Northern Cyprus.

19. Gallegos, EC., Ovalle-Berumen, F., \& Gomez-Meza, MV. (2006). Metabolic Control of Adults with Type 2 Diabetes Mellitus through Education and Counseling. J Nurs Scholars 38(4):344-51.

20. Hiçdurmaz, D., \& Öz, F. (2009). Coping Styles of Patients Taking Hemodialysis and Continuous Ambulatory Peritoneal Dialysis Treatment. Hacettepe Üniversitesi Sağhle Bilimleri Fakültesi Hemşirelike D. 1-16.

21. Huang, ES., Gorawara-Bhat, R., \& Chin, MH. (2005). Self-reported Goals of Older Patients with Type 2 Diabetes Mellitus. J Am Geriatr Soc. 53:306-11.

22. Jaarsma, T., Halfens, R., Tan, F., Abu-Saad, HH., Dracup, K., \& Diederiks, J.(2000). Selfcare and Quality of Life in Patients with Advanced Heart Failure: The Effect of a Supportive Educational Intervention. Heart Lung. 29(5):319-30.

23. Jansen, DL., Rijken, M., Heijmans, M., \& Boeschoten, EW.(2010). Perceived Autonomy and Self-esteem in Dutch Dialysis Patients: The Importance of Illness and Treatment Perceptions. Psychol Health. 25(6):733-49.

24. Kara, B. (2006). Validity and Reliability Study of the Hemodialysis Stressor Scale. Zonguldak Karaelmas Üniv Zonguldak Sağhlk YO Sağhlk. Eğitim Araș D. 2(2):64-71. 
Firat Kılıç, H., Alpar Ş. E. (2016). The effect of group training implemented on hemodialysis patients for their stress management, psychosocial adjustment and self-care strength. International Journal of Human Sciences, 13(1), NNN-NNN. doi:10.14687/ijhs.v13i1.3422

25. Kara, B. (2007). Adjustment to Treatment in Hemodialysis Patients: A Multi-faceted Approach. Gülbane Tip D . 49(2):132-6.

26. Kara, B. \& İşcan, B. (2006). The Stressors Perceived in Hemodialysis Patients by Nurses. Nefroloji Hemsireliği D. Kasım-Şubat:57-64.

27. Klang, B,. Björvell, H., Berglund, J., Sundstedt, C., \& Clyne, N. (1998). Predialysis Patient Education: Effects on Functioning and Well-being in Uraemic Patients. J Adv Nurs. 28(1):36-44.

28. Kutner, NG., Zhang, R., McClellan, WM., \& Cole, SA. (2002). Psychosocial Predictors of Non-compliance in Haemodialysis and Peritoneal Dialysis Patients. Nephrol Dial Transplant. 17(1):93-9.

29. Lev, EL, \& Owen, SV. (1998). A Prospective Study of Adjustment to Hemodialysis. ANNA J. 25(5):495-503.

30. Manns, BJ., Taub. K., Vanderstraeten, C., Jones, H., Mills, C., Visser, M et al.(2005). The Impact of Education on Chronic Kidney Disease Patients' Plans to Initiate Dialysis with Self-care Dialysis: A Randomized Trial. Kidney Int. 68(4):1777-83.

31. Mok, E., \& Tam, B.(2001). Stressors and Coping Methods Among Chronic Haemodialysis Patients in Hong Kong. J Clin Nurs . 10(4):503-11.

32. Molaison, EF., \& Yadrick, MK. (2003) Stages of Change and Fluid Intake in Dialysis Patients. Patient Educ Couns . 49(1):5-12.

33. Mollaoğlu, M.(2005). Self-care Strength and Depression in Patients on which Hemodialysis was Implemented. Nefroloji Hemsireliğg D . 12:55-60.

34. Mollaoğlu, M. (2011). Disability, Activities of Daily Living and Self-Efficacy in Dialysis Patients. TAF Prev Med Bull, 10(2):181-6.

35. Ören, B. (2010). Investigation of the Factors that Effect the Quality of Life and Self-care Strength of Hemodialysis and Peritoneal Dialysis Patients. PhD diss., Istanbul University, Institute of Health Sciences, Istanbul.

36. Ören, B., \& Enç, N. (2013). Quality of Life in Chronic Haemodialysis and Peritoneal Dialysis Patients in Turkey and Related Factors. Int J Nurs Prac. 19(6):547-556.

37. Özçürümez, G., Tanriverdi, N., \& Zileli. L. (2003). The Psychiatric and Psychosocial Aspects of Chronic Renal Insufficiency. Türk Psikiyatri Dergisi, 14(1):72-80.

38. Parvan, K., Ahangar, R., Hosseini, FA., Abdollahzadeh, F., Ghojazadeh, M, \& Jasemi, M. (2015). Coping methods to stress among patients on hemodialysis and peritoneal dialysis. Saudi J Kidney Dis Transpl. 26(2):255-62.

39. Rosner, F. (2006). Patient Noncompliance: Causes and Solutions. Mt Sinai J Med . 73:553-9.

40. Suet-Ching, WL.(2001). The Quality of Life for Hong-Kong Dialysis Patients. J Adv Nurs 35(2):218-27.

41. Takaki, J., \& Yano, E. (2006). Possible Gender Differences in the Relationships of Selfefficacy and the Internal Locus of Control with Compliance in Hemodialysis Patients. Behav Med. 32:5-11.

42. Tsay, SL., \& Healstead, M.(2001). Self-care, Self-efficacy, Depression and Quality of Life Among Patients Receiving Hemodialysis in Taiwan. Int J Nurs Stud. 39(3): 245-51.

43. Tsay, SL., \& Lee, YC. (2005). Effects of an Adaptation Training Programme for Patients with End-stage Renal Disease. J Adv Nurs, 50(1):39-46.

44. Türkmen, SN., \& Çam., MO. (2012). Evaluation of the Impact of Psychological Therapy/Education on the Psychosocial Adaptation of Patients with Myocardial Infarction. J Psychiatr Nurs. 3(3):105-15.

45. Vicdan, AK., \& Karabacak., BG. (2014). The Use of Patient Education Roy Adaptation Model Haemodialysis. Int J Human Sci. 11(2):209-20. doi: 10.14687/ijhs.v11i2.2729

46. Yurtsever, S., \& Kuyurtar, F.(2005). Exhaustion and Self care in Hemodialysis Patients. Nefroloji Hemsireliği. 18:26-32. 
Firat Kilıç, H., Alpar Ş. E. (2016). The effect of group training implemented on hemodialysis patients for their stress management, psychosocial adjustment and self-care strength. International Journal of Human Sciences, 13(1), NNN-NNN. doi:10.14687/ijhs.v13i1.3422

Table 2 Distribution of sociodemographic characteristics of the patients $(\mathrm{n}=90)$

\begin{tabular}{|lcc|}
\hline Sociodemographic & $\mathrm{n}$ & $\%$ \\
Institution & & \\
Institution 1 & 75 & 83.3 \\
Institution 2 & 15 & 16.7 \\
Gender & 44 & 48.9 \\
Female & 46 & 51.1 \\
Male & & \\
Age & 12 & 13.3 \\
18-44 vears of age & 36 & 40.0 \\
45-64 years of age & 27 & 30.0 \\
65-74 vears of age & 15 & 16.7 \\
75 years or age and older & & \\
Marital status & 77 & 85.6 \\
Married & 13 & 14.4 \\
Single & 16 & 17.8 \\
Work Status & 74 & 82.2 \\
Works & & 21.1 \\
Does not work & 19 & 46.7 \\
Periods of hemodialvsis & 42 & 24.4 \\
6-11 months & 22 & 7.8 \\
1-4 vears & 7 & 12.2 \\
5-9 vears & & $\underline{84.5}$ \\
10 vears and more & 11 & 3.3 \\
Frequency of bemodialvsis & 76 & $\mathbf{1 0 0}$ \\
2 times/week & 3 & \\
3 times/week & $\mathbf{9 0}$ & \\
4 times/week & & \\
Total & & \\
\end{tabular}

Table 3. Differences in the point averages of the scales before and after training $(n=90)$

\begin{tabular}{|ccccc|}
\hline Scale & $\begin{array}{c}\text { Before } \\
\overline{\mathrm{X}} \pm \mathbf{S}\end{array}$ & $\begin{array}{c}\text { After } \\
\overline{\mathrm{X}} \pm \mathbf{S}\end{array}$ & Z value* & p value \\
HSS total points & $107.87 \pm 14.96$ & $83.18 \pm 12.34$ & -8.236 & $.000^{* *}$ \\
H1 & $89.88 \pm 12.48$ & $71.31 \pm 11.01$ & -8.237 & $.000^{* *}$ \\
H2 & $18.00 \pm 3.49$ & $13.94 \pm 2.44$ & -7.716 & $.000^{* *}$ \\
PAIS-SR total points & $83.95 \pm 19.41$ & $60.15 \pm 17.01$ & -8.240 & $.000^{* * *}$ \\
P 1 & $16.82 \pm 4.17$ & $11.84 \pm 2.99$ & -8.115 & $.000^{* * *}$ \\
P 2 & $12.13 \pm 3.09$ & $9.76 \pm 2.26$ & -7.579 & $.000^{* * *}$ \\
P 3 & $12.90 \pm 4.56$ & $8.43 \pm 3.20$ & -8.012 & $.000^{* * *}$ \\
P 4 & $12.16 \pm 4.29$ & $9.72 \pm 3.55$ & -7.110 & $.000^{* * *}$ \\
P 5 & $7.26 \pm 2.65$ & $4.77 \pm 1.91$ & -7.528 & $.000^{* * *}$ \\
P 6 & $11.13 \pm 4.03$ & $7.05 \pm 2.96$ & -7.930 & $.000^{* * *}$ \\
P 7 & $11.43 \pm 4.07$ & $7.11 \pm 2.77$ & -8.181 & $.000^{* * *}$ \\
SSS total points & $16.20 \pm 7.22$ & $31.46 \pm 4.01$ & -8.197 & $.000^{* * *}$ \\
\hline
\end{tabular}

*The Wilcoxon Signed-Rank test was used. ${ }^{* *} \mathrm{p}<.001 * * * \mathrm{p}<.05$ 
Firat Kilıç, H., Alpar Ş. E. (2016). The effect of group training implemented on hemodialysis patients for their stress management, psychosocial adjustment and self-care strength. International Journal of Human Sciences, 13(1), NNN-NNN. doi:10.14687/ijhs.v13i1.3422

Table 4. Relationship among the HSS, SSS and PAIS-SR scale point averages $(\mathrm{n}=90)$

\begin{tabular}{|c|c|c|c|c|}
\hline \multirow{2}{*}{ Variables } & \multicolumn{2}{|c|}{ Before } & \multicolumn{2}{|l|}{ After } \\
\hline & $\mathbf{r}^{*}$ & $\mathrm{p}$ & $\mathrm{r}^{*}$ & $\mathrm{p}$ \\
\hline & \multicolumn{2}{|c|}{ SSS total points } & \multicolumn{2}{|c|}{ SSS total points } \\
\hline H1 & -.71 & $.000 * *$ & -.44 & $.000 * *$ \\
\hline $\mathbf{H} 2$ & -.47 & $.000^{* *}$ & -.33 & $.000 * *$ \\
\hline \multirow[t]{2}{*}{ HSS total points } & -.70 & $.000^{* *}$ & -.44 & $.000 * *$ \\
\hline & \multicolumn{2}{|c|}{ HSS total points } & \multicolumn{2}{|c|}{ HSS total points } \\
\hline P 1 & .53 & $.000^{* * *}$ & .41 & $.000^{* * *}$ \\
\hline P 2 & .64 & $.000^{* * *}$ & .51 & $.000 * * *$ \\
\hline P 3 & .57 & $.000^{* * *}$ & .51 & $.000^{* * *}$ \\
\hline P 4 & .42 & $.000^{* * *}$ & .27 & $.009^{* * *}$ \\
\hline P 5 & .36 & $.000^{* * *}$ & .205 & .050 \\
\hline P 6 & .37 & $.000 * * *$ & .29 & $.005^{* * *}$ \\
\hline P 7 & .47 & $.000^{* * *}$ & .45 & $.000^{* * *}$ \\
\hline \multirow[t]{2}{*}{ PAIS-SR total points } & .67 & $.000 * * *$ & .58 & $.000 * * *$ \\
\hline & \multicolumn{2}{|c|}{ SSS total points } & \multicolumn{2}{|c|}{ SSS total points } \\
\hline $\mathbf{P} 1$ & -.56 & $.000 * * *$ & -.29 & $000 * * *$ \\
\hline P 2 & -.54 & $.000 * * *$ & -.26 & $.000 * * *$ \\
\hline P 3 & -.55 & $.000^{* * *}$ & -.31 & $.000 * * *$ \\
\hline P 4 & -.31 & .003 & -.127 & .234 \\
\hline P 5 & -.38 & $.000^{* * *}$ & -.31 & .003 \\
\hline P 6 & .199 & .060 & -.21 & 050 \\
\hline $\mathbf{P} 7$ & -.45 & $.000^{* * *}$ & -.35 & $.001^{* * *}$ \\
\hline PAIS-SR total points & -.59 & $.000^{* * *}$ & -.39 & $.000 * * *$ \\
\hline
\end{tabular}

* Spearman's Rank Correlation Coefficient analysis was used

$* * \mathrm{p}=.001$

$* * * \mathrm{p}=.01$ 
Fırat Kilıç, H., Alpar Ş. E. (2016). The effect of group training implemented on hemodialysis patients for their stress management, psychosocial adjustment and self-care strength . International Journal of Human Sciences, 13(1), 754-767. doi:10.14687/ijhs.v13i1.3422

Table 5 Distribution according to some variables of the difference among the HSS scale point averages of the patients before and after training $(\mathrm{n}=90)$

\begin{tabular}{|c|c|c|c|c|c|c|c|}
\hline \multirow[b]{3}{*}{ Variables } & \multirow[b]{3}{*}{$\mathbf{n}$} & \multicolumn{6}{|c|}{ Hemodialysis Stressor Scale } \\
\hline & & \multicolumn{2}{|c|}{ General } & \multicolumn{2}{|c|}{ Psychosocial subscale } & \multicolumn{2}{|c|}{ Physiological subscale } \\
\hline & & Avg. \pm SD & Significance & Avg. \pm SD & Significance & Avg. \pm SD & Significance \\
\hline \multicolumn{8}{|l|}{ Institution * } \\
\hline Institution 1 & 75 & $24.88 \pm 10.48$ & \multirow{2}{*}{$\mathrm{P}=.095$} & $18.94 \pm 9.13$ & \multirow{2}{*}{$\mathrm{P}=.121$} & $3.89 \pm 3.02$ & \multirow{2}{*}{$\mathrm{P}=.066$} \\
\hline Institution 2 & 15 & $23.86 \pm 8.79$ & & $16.73 \pm 8.02$ & & $4.86 \pm 2.55$ & \\
\hline \multicolumn{8}{|l|}{ Age ** } \\
\hline $18-44$ & 12 & $25.50 \pm 7.41$ & \multirow{4}{*}{$\mathrm{P}=.599$} & $19.41 \pm 6.41$ & & $4.33 \pm 2.70$ & \multirow{4}{*}{$\mathrm{P}=.712$} \\
\hline $45-64$ & 36 & $24.00 \pm 8.79$ & & $18.16 \pm 8.38$ & & $3.63 \pm 3.02$ & \\
\hline $65-74$ & 27 & $24.51 \pm 13.65$ & & $18.37 \pm 11.31$ & $\mathrm{P}=.593$ & $4.03 \pm 3.40$ & \\
\hline $75+$ & 15 & $26.13 \pm 8.51$ & & $19.26 \pm 7.91$ & & $4.86 \pm 2.09$ & \\
\hline \multicolumn{8}{|l|}{ Gender* } \\
\hline Female & 44 & $27.22 \pm 8.19$ & \multirow{2}{*}{$\mathrm{P}=.263$} & $21.11 \pm 7.32$ & \multirow{2}{*}{$\mathrm{P}=.032$} & $4.13 \pm 2.55$ & \multirow{2}{*}{$\mathrm{P}=.110$} \\
\hline Male & 46 & $22.30 \pm 11.35$ & & $16.15 \pm 9.75$ & & $3.97 \pm 3.32$ & \\
\hline \multicolumn{8}{|l|}{ Marital Status* } \\
\hline Married & 77 & $24.84 \pm 9.78$ & \multirow{2}{*}{$\mathrm{P}=.717$} & $19.00 \pm 11.18$ & \multirow{2}{*}{$\mathrm{P}=.625$} & $4.23 \pm 2.86$ & \multirow{2}{*}{$\mathrm{P}=.867$} \\
\hline Single & 13 & $23.92 \pm 12.73$ & & $18.50 \pm 8.61$ & & $3.00 \pm 3.39$ & \\
\hline \multicolumn{8}{|l|}{ Work Status* } \\
\hline Works & 16 & $22.75 \pm 7.77$ & \multirow[b]{2}{*}{$\mathrm{P}=.132$} & $17.12 \pm 6.42$ & \multirow[b]{2}{*}{$\mathrm{P}=.079$} & $3.50 \pm 2.92$ & \multirow{2}{*}{$\mathrm{P}=.403$} \\
\hline Does not work & 74 & $25.13 \pm 10.63$ & & $18.89 \pm 9.42$ & & $4.17 \pm 2.97$ & \\
\hline
\end{tabular}

* The Mann-Whitney U-test and **Kruskal Wallis H-Testi was used. 
Fırat Kilıç, H., Alpar Ş. E. (2016). The effect of group training implemented on hemodialysis patients for their stress management, psychosocial adjustment and self-care strength . International Journal of Human Sciences, 13(1), 754-767. doi:10.14687/ijhs.v13i1.3422

Table 6 Differences according to some variables between the PAIS-SR scale point averages of the patients before and after training ( $\mathrm{N}=90)$

\begin{tabular}{|c|c|c|c|c|c|c|c|c|c|}
\hline \multirow{3}{*}{ Variables } & \multirow[b]{3}{*}{$\mathbf{n}$} & \multicolumn{8}{|c|}{ Psychosocial Adjustment to Illness Scale-Self-Report } \\
\hline & & General & P1 & P2 & P3 & P4 & P5 & P6 & P7 \\
\hline & & Avg. \pm SD & Avg. \pm SD & Avg. \pm SD & Avg. \pm SD & Avg. \pm SD & Avg. \pm SD & Avg. \pm SD & Avg. \pm SD \\
\hline \multicolumn{10}{|l|}{ Institution* } \\
\hline Institution 1 & 75 & $22.08 \pm 15.73$ & $4.76 \pm 2.55$ & $2.10 \pm 1.83$ & $4.00 \pm 2.52$ & $2.45 \pm 2.26$ & $2.20 \pm 1.82$ & $3.88 \pm 2.70$ & $4.29 \pm 2.44$ \\
\hline Institution 2 & 15 & $32.40 \pm 10.02$ & $6.06 \pm 2.63$ & $3.66 \pm 1.34$ & $6.80 \pm 2.30$ & $2.40 \pm 1.95$ & $3.93 \pm 2.91$ & $5.06 \pm 3.05$ & $4.46 \pm 3.11$ \\
\hline Significance & & $\mathrm{P}=.004$ & $\mathrm{P}=.095$ & $\mathrm{P}=.007$ & $\mathrm{P}=.042$ & $\mathrm{P}=.121$ & $\mathrm{P}=.267$ & $\mathrm{P}=.366$ & $\mathrm{P}=.001$ \\
\hline \multicolumn{10}{|l|}{ Age** } \\
\hline $18-44$ & 12 & $26.00 \pm 15.20$ & $5.08 \pm 3.77$ & $2.08 \pm 1.78$ & $4.91 \pm 2.98$ & $1.41 \pm 1.78$ & $3.16 \pm 3.21$ & $4.25 \pm 3.04$ & $5.08 \pm 3.75$ \\
\hline $45-64$ & 36 & $22.25 \pm 20.58$ & $5.27 \pm 2.36$ & $2.55 \pm 1.97$ & $4.72 \pm 2.89$ & $2.44 \pm 1.91$ & $2.69 \pm 1.75$ & $3.83 \pm 3.11$ & $4.36 \pm 2.35$ \\
\hline $65-74$ & 27 & $23.77 \pm 10.12$ & $4.74 \pm 2.56$ & $2.03 \pm 1.60$ & $3.81 \pm 2.14$ & $2.48 \pm 2.56$ & $1.92 \pm 1.89$ & $4.18 \pm 2.54$ & $4.22 \pm 2.34$ \\
\hline $75+$ & 15 & $25.80 \pm 7.65$ & $4.60 \pm 2.26$ & $2.73 \pm 2.05$ & $4.66 \pm 2.84$ & $3.20 \pm 2.36$ & $2.46 \pm 2.26$ & $4.33 \pm 2.31$ & $3.80 \pm 2.30$ \\
\hline Significance & & $\mathrm{P}=.454$ & $\mathrm{P}=.984$ & $\mathrm{P}=.298$ & $\mathrm{P}=.773$ & $\mathrm{P}=.658$ & $\mathrm{P}=.886$ & $\mathrm{P}=.114$ & $\mathrm{P}=.482$ \\
\hline \multicolumn{10}{|l|}{ Gender* } \\
\hline Female & 48 & $25.31 \pm 19.88$ & $5.56 \pm 2.50$ & $2.90 \pm 1.69$ & $4.88 \pm 3.19$ & $2.56 \pm 2.33$ & $2.65 \pm 2.60$ & $4.81 \pm 2.84$ & $4.18 \pm 2.59$ \\
\hline Male & 42 & $22.34 \pm 9.26$ & $4.41 \pm 2.58$ & $1.84 \pm 1.86$ & $4.06 \pm 2.18$ & $2.32 \pm 2.09$ & $2.32 \pm 1.55$ & $3.36 \pm 2.55$ & $4.45 \pm 2.51$ \\
\hline Significance & & $\mathrm{P}=.140$ & $\mathrm{P}=.539$ & $\mathrm{P}=.435$ & $\mathrm{P}=.521$ & $\mathrm{P}=.127$ & $\mathrm{P}=.769$ & $\mathrm{P}=696$ & $\mathrm{P}=146$ \\
\hline \multicolumn{10}{|l|}{ Marital Status* } \\
\hline Married & 77 & $24.06 \pm 17.17$ & $5.14 \pm 2.53$ & $2.42 \pm 1.80$ & $4.42 \pm 2.59$ & $2.51 \pm 2.16$ & $2.61 \pm 2.19$ & $4.06 \pm 2.86$ & $4.44 \pm 2.62$ \\
\hline Single & 13 & $23.12 \pm 9.51$ & $4.00 \pm 2.88$ & $2.00 \pm 2.12$ & $4.69 \pm 3.30$ & $2.00 \pm 2.41$ & $1.76 \pm 1.53$ & $4.15 \pm 2.33$ & $3.61 \pm 1.93$ \\
\hline Significance & & $\mathrm{P}=.223$ & $\mathrm{P}=.214$ & $\mathrm{P}=.359$ & $\mathrm{P}=.422$ & $\mathrm{P}=.217$ & $\mathrm{P}=.958$ & $\mathrm{P}=.127$ & $\mathrm{P}=.972$ \\
\hline \multicolumn{10}{|l|}{ Work Status* } \\
\hline Works & 16 & $21.81 \pm 9.66$ & $3.62 \pm 1.74$ & $1.68 \pm 1.99$ & $3.56 \pm 2.85$ & $1.62 \pm 1.63$ & $2.43 \pm 1.67$ & $4.25 \pm 2.90$ & $4.68 \pm 2.12$ \\
\hline Does not work & 74 & $24.22 \pm 16.37$ & $5.27 \pm 2.67$ & $2.51 \pm 1.79$ & $4.66 \pm 2.62$ & $2.62 \pm 2.28$ & $2.50 \pm 2.22$ & $4.04 \pm 2.77$ & $4.24 \pm 2.63$ \\
\hline Significance & & $\mathbf{P}=.305$ & $\mathrm{P}=.001$ & $\mathrm{P}=.168$ & $\mathrm{P}=.058$ & $\mathrm{P}=.395$ & $\mathrm{P}=.283$ & $\mathrm{P}=.674$ & $\mathrm{P}=.395$ \\
\hline
\end{tabular}

*The Mann-Whitney U-test and **Kruskal Wallis H-Testi was us 